\title{
Enhancement of the thermooxidative degradability of polystyrene by chemical modification
}

\author{
Gabriela Botelho ${ }^{\mathrm{a}, *}$, Arlete Queirós ${ }^{\mathrm{a}}$, Ana Machado ${ }^{\mathrm{b}}$, \\ Paulo Frangiosa ${ }^{\mathrm{c}}$, José Ferreira ${ }^{\mathrm{a}}$ \\ a Departamento de Quimica, Universidade do Minho, Campus de Gualtar, 4710-057 Braga, Portugal \\ ${ }^{\mathrm{b}}$ Departamento de Engenharia de Polimeros, Universidade do Minho, Campus de Azurém, 4800-058 Guimarães, Portugal \\ ${ }^{\mathrm{c}}$ Departamento de Quimica Fundamental, Universidade de São Paulo, CP 26077, 05599-970 São Paulo, Brazil
}

Received 26 March 2004; received in revised form 24 May 2004; accepted 31 May 2004

\begin{abstract}
A comparative study was conducted into the thermooxidative degradation of polystyrene (PS) and polystyrene modified with different percentages $(5,10$ and 15$)$ of $-\mathrm{CH}_{2}(\mathrm{C}=\mathrm{O}) \mathrm{CH}_{2} \mathrm{CH}_{2}-$ units (MPS). The influence of the chemical modification on the thermooxidative degradation was assessed by oxygen uptake, FTIR and UV-vis spectroscopy, DSC and viscometry. The oxidation rate, yellowing and formation of oxidation products were accelerated in MPS. The $T_{\mathrm{g}}$ values for undegraded PS and MPS were very similar, suggesting that the mechanical properties are little affected by the modification. The drastic decrease in $T_{\mathrm{g}}$ observed for degraded MPS was related with extensive chain cleavage. This was confirmed by the more pronounced decrease of the intrinsic viscosity of degraded MPS. These results clearly indicated that the thermooxidative degradability of polystyrene could be enhanced after the insertion of units containing carbonyl groups within the polystyrene chain.
\end{abstract}

(C) 2004 Elsevier Ltd. All rights reserved.

Keywords: Polystyrene; Thermooxidative degradation; Chemical modification

\section{Introduction}

Interest in degradable plastics has been increasing enormously as a result of the enlarging volume of municipal solid waste, the decreasing landfill capacity for its disposal, and because plastic products are among the most visible forms of trash. To overcome this problem, degradable plastics must be developed. It is well known that polymers are very different as far as their inherent sensitivity to oxidation is concerned. Generally, differences in stability arise from a variety of

* Corresponding author. Tel.: +351 253604058; fax: +351 253678983.

E-mail address: gbotelho@quimica.uminho.pt (G. Botelho). chemical structures, manufacturing processes and polymer morphology [1].

Several studies on the thermal degradation of polystyrene (PS) have been published [2,3] and the predominant mechanism is accepted to be that of random chain scission followed by intermolecular transfer, with smaller amounts of unzipping and intramolecular transfer. More recently, blend component interactions involving PS have been reported [4-7] in order to change the thermal stability. It has been found that, in blends of PS and poly(vinyl methyl ether), the PVME component ages independently of PS and is responsible for the ageing effects [5].

The photodegradation of PS has been extensively studied [8-10] and a mechanism accounting for the photoproducts has been established [9]. More recently 
the photo-oxidation of PS/PVME blends [11], $\operatorname{poly}(\alpha-$ methylstyrene) [12] and PS modified by addition of benzophenone and acetophenone have also been investigated [13].

Following previous studies [14] on the photodegradation of PS and copolymers of modified styrene (MPS) by insertion of different amounts $(5,10$ and $15 \%)$ of $-\mathrm{CH}_{2}(\mathrm{C}=\mathrm{O}) \mathrm{CH}_{2} \mathrm{CH}_{2}-$ units in the backbone, the thermooxidative degradation of these polymers, at $150{ }^{\circ} \mathrm{C}$, was undertaken. Fig. 1 shows the chemical structure of the MPS segment containing the modification. The objective of this study was to investigate the influence of the chemical modification on the degradability of PS, aiming at the improvement of the decomposition of this polymer when exposed to natural environment.

\section{Experimental}

\subsection{Materials}

Powder samples of PS and MPS with ca. 5, 10 and $15 \%$ modification (MPS5, MPS10 and MPS15) were prepared, according to the literature $[15,16]$, and supplied by University of São Paulo (Brazil). Polymers were prepared by free-radical polymerization using azobis-isobutyronitrile as initiator, starting with $0,5,10$ and $15 \%$ of the comonomer, 2-methoxy-1,3-butadiene, in relation to styrene. The resulting polymers were submitted to hydrolysis, resulting in PS containing different amounts of carbonyl groups inserted in the backbone. The final percentage of modification was obtained by elemental analysis $[14,17]$. The samples were dried and stored under vacuum, without influence of light.

\subsection{Instrumentation}

Degradation experiments were carried out in duplicate in a closed vessel filled with pure oxygen in an oil bath at $150{ }^{\circ} \mathrm{C}$. The pressure changes in the vessel were measured with a DRUCK PDCR 910 pressure transducer (for more details see Ref. [18]). Two experiments were carried out independently and the results obtained in both cases were reproducible. At various degradation times samples were taken and characterized using the analytical techniques indicated below.

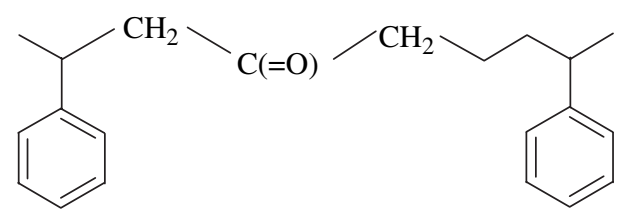

Fig. 1. Chemical structure of the MPS segment containing the modification.
The UV spectra were recorded on a Shimadzu UV$2501 \mathrm{PC}$ spectrophotometer using $0.013 \mathrm{~g} \mathrm{~mL}^{-1}$ solutions in THF. Infrared spectra were recorded on a Bomen spectrophotometer, using 10 scans and $4 \mathrm{~cm}^{-1}$ resolution, as $\mathrm{KBr}$ pellets.

The inherent viscosity, $\eta_{\text {inh }}$, was determined from $0.012 \mathrm{~g} \mathrm{~mL}^{-1}$ solutions in toluene using a capillary Ubbelohde, at $25 \pm 1{ }^{\circ} \mathrm{C}$.

The thermal behaviour of the samples was evaluated using a Perkin-Elmer DSC 7 differential scanning calorimeter. Polymer samples of ca. $10 \mathrm{mg}$ were heated from 30 to $120^{\circ} \mathrm{C}$, at a constant rate of $10{ }^{\circ} \mathrm{C} \mathrm{min}^{-1}$ using high purity nitrogen as a purge gas.

\section{Results}

\subsection{Oxygen uptake}

The oxygen uptake of PS and MPS was measured during the thermooxidative degradation at $150^{\circ} \mathrm{C}$ and the results obtained are presented in Fig. 2. In all samples the oxidation rate was found to increase right from the beginning of the experiment. After an oxygen uptake of about $1500 \mathrm{mmol} \mathrm{kg}^{-1}$ the oxidation was stopped as it led to heavily degraded materials [19].

Under these experimental conditions the time required to an oxygen uptake of $600 \mathrm{mmol} \mathrm{kg}^{-1}$ is ca $230 \mathrm{~h}$ for MPS15, $330 \mathrm{~h}$ for MPS10, $390 \mathrm{~h}$ for MPS5 and $420 \mathrm{~h}$ for PS. It was observed that oxidation was enhanced by the presence of the aliphatic ketone segments within the polymer matrix as the oxygen uptake was always higher for the MPS samples than for pure PS. Although MPS15 had the highest oxidation rate the oxygen uptake was not proportional to the comonomer content of the polymer. In fact, higher differences were observed for MPS15 than for MPS5 and MPS10.

\section{2. $U V-v i$ spectroscopy}

Samples of PS and MPS collected with time were analysed by UV-vis spectroscopy. In all spectra an

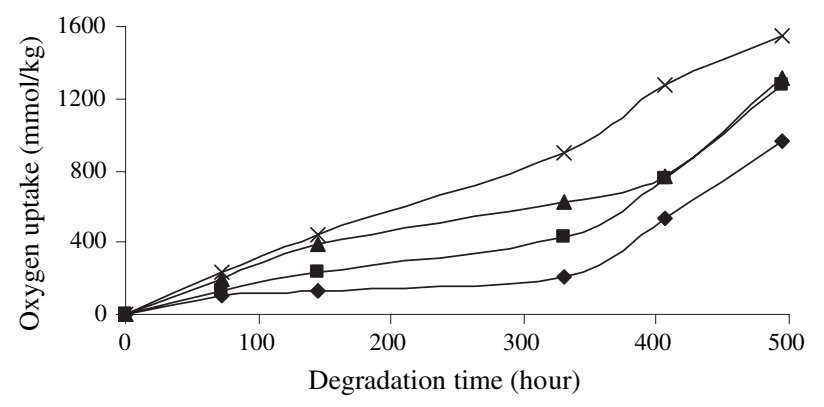

Fig. 2. Oxygen uptake vs. degradation time for ( $\bullet$ PS, ( $\boldsymbol{\square})$ MPS5, (ム) MPS10 and $(\times)$ MPS15. 
increase in absorption was detected, without showing any defined maximum from the near-UV domain till the visible region that is responsible for the observed yellowing [20]. In Fig. 3 the absorbance, at $400 \mathrm{~nm}$, of $0.013 \mathrm{~g} \mathrm{~mL}^{-1}$ solutions along degradation is displayed. It could be observed that, in contrast with PS, yellowing was enhanced in all modified samples, increasing with the carbonyl content. However, a more pronounced effect could be detected for MPS15, in agreement with the oxygen uptake profiles shown in Fig. 2. This indicates that the oxygen consumption of the polymer samples, leads to the formation of chromophoric groups responsible for the observed yellowing.

\subsection{FTIR spectroscopy}

FTIR measurements were used to monitor the changes in the chemical structure associated with the degradation. The FTIR spectra of all degraded samples of MPS15 showed bands in the hydroxyl $\left(3700-3200 \mathrm{~cm}^{-1}\right)$ and carbonyl $\left(1800-1600 \mathrm{~cm}^{-1}\right)$ regions (Fig. 4a and b). MPS5 and MPS10 only showed bands in the carbonyl region.

For PS only the most degraded samples showed two very weak bands at 3540 and $3450 \mathrm{~cm}^{-1}$. These bands were also present in photodegraded PS and, according to Mailhot and Gardette [8,9], are due to alcohols and hydroperoxides, respectively. In contrast, MPS15 degraded samples show broad and increasing bands in the $3700-3200 \mathrm{~cm}^{-1}$ region (Fig. 4a) that can also be attributed to $\mathrm{OH}$ groups in hydroperoxides and alcohols. Thus, build-up of hydroperoxides occurs predominantly in the aliphatic segment.

The shapes of the FTIR bands of degraded MPS and PS, appearing in the carbonyl stretching region, are very different. The spectra of PS showed an increasing band at $1688 \mathrm{~cm}^{-1}$, attributed previously to the carbonyl group of an aromatic end chain ketone or to acetophenone [8]. The spectra of MPS presented several maxima and shoulders at 1730, 1725, 1710, 1698 and $1688 \mathrm{~cm}^{-1}$ (Fig. 4b). A band at $1712 \mathrm{~cm}^{-1}$, due to the carbonyl ketone group in MPS, was already visible in all samples

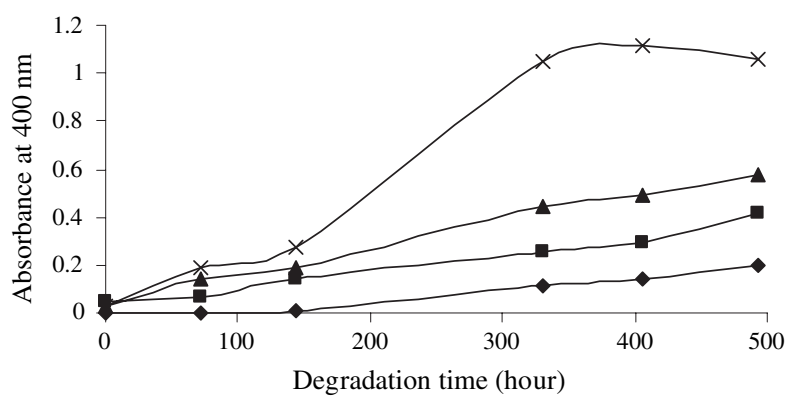

Fig. 3. Absorbance at $400 \mathrm{~nm}$ vs. degradation time for $(\diamond)$ PS, MPS5, (ム) MPS10 and (×) MPS15.
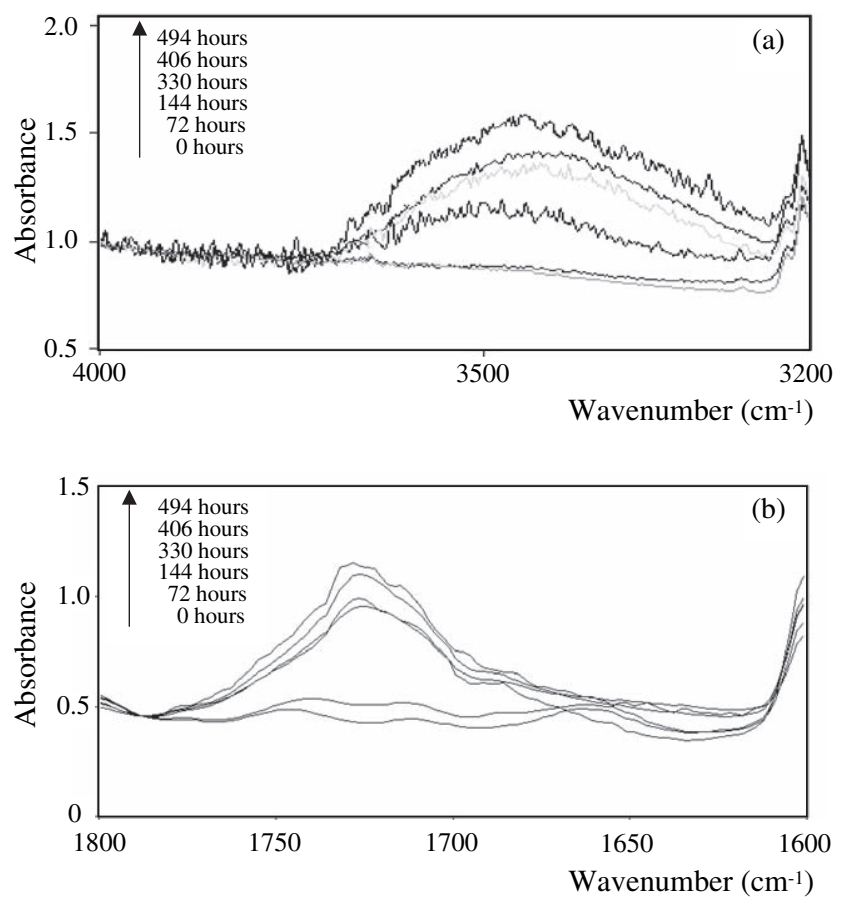

Fig. 4. Evolution of the FTIR spectra of MPS15 (a) hydroxyl region and (b) carbonyl region, during the thermooxidative degradation.

prior to oxidation [14]. Although this band hampers the observation of a band due to acetic acid, expected at $1710 \mathrm{~cm}^{-1}$ [8], its presence is visible in the spectra of the more degraded samples. The band at $1725 \mathrm{~cm}^{-1}$ was assigned to new aliphatic ketones [12] that can be originated in the aliphatic segment.

The carbonyl index, defined as the ratio of $A_{1725(t) /}$ $A_{1725(0)}$, in which $A_{1725(t)}$ and $A_{1725(0)}$ were the absorbances at $1725 \mathrm{~cm}^{-1}$ after and before degradation, respectively, was used as a measure of the thermooxidative degradation. The carbonyl indices for MPS5, MPS10 and MPS15 are plotted against the degradation time in Fig. 5. It can be observed that the carbonyl indices are very similar in the first $72 \mathrm{~h}$. However, for

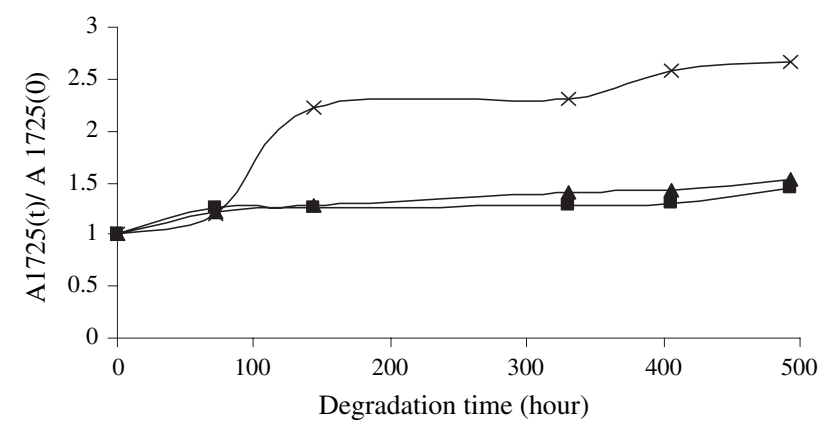

Fig. 5. Changes of carbonyl index vs. degradation time for ( $\boldsymbol{\square})$ MPS5, (ム) MPS10 and (X) MPS15. 
MPS15 a rapid increase up to $144 \mathrm{~h}$, followed by a smoother increase, was observed. This last stage can be explained if the aliphatic ketone undergoes further reaction whose rate is lower than its rate of formation.

It can be concluded that, although the degradation increases with the percentage of modification a major effect was observed for MPS15.

The band at $1688 \mathrm{~cm}^{-1}$ and a new band at $1515 \mathrm{~cm}^{-1}$, both characteristic of degraded PS [11], increased less in MPS than in PS samples degraded for the same time. This indicates that the degradation of the PS units was not enhanced in MPS.

\subsection{Viscosity measurements}

Fig. 6 displays the changes of the intrinsic viscosity with degradation for PS and MPS. The low decrease observed for PS indicates that, in the experimental conditions used, the variation of molecular weight was small. On the other hand, over the $494 \mathrm{~h}$ of degradation, the intrinsic viscosity decreased from ca 20 to $11.5,10.8$ and $8.0 \mathrm{~mL} \mathrm{~g}^{-1}$ for MPS5, MPS10 and MPS15, respectively. The observed decrease is related to the formation of lower molecular weight products after chain breakages. It is also to be noted that the extent of bond breakage in both MPS5 and MPS10 is very similar, but a more pronounced effect could be observed for MPS15. These results are in agreement with those obtained for the carbonyl index discussed above. This indicates that the aliphatic ketone responsible for higher indices obtained for MPS15 is formed after bond breaking occurring mainly within the aliphatic carbonyl segment. Carbonyl groups, due to their electron withdrawing effect, can facilitate oxidation in nearby methylene groups. On the other hand, due to their size and polarity, they obstruct crosslinking, that is known to occur within the ethylene segment in thermooxidised SEBS block copolymer [21].

Previous results on the photodegradation of these modified polymers [17] showed that the average number

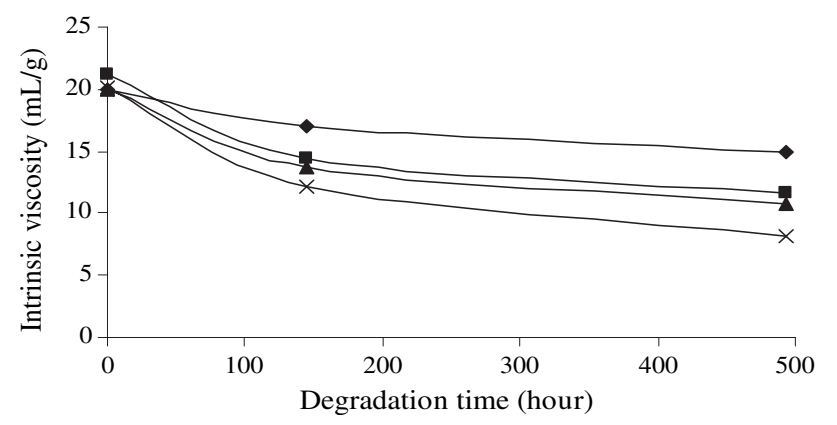

Fig. 6. Intrinsic viscosity vs. degradation time for ( ) PS, ( $\boldsymbol{\square})$ MPS5, ( $\Delta)$ MPS10 and $(\times)$ MPS15. of breaks per chain increased from 2 in MPS5 and 4 in MPS10 to 12 in MPS15.

\subsection{DSC measurements}

The thermal behaviour of PS, with and without chemical modification, was studied by DSC.

For undegraded MPS and PS the glass transition temperatures $\left(T_{\mathrm{g}}\right)$ are 102 and $98{ }^{\circ} \mathrm{C}$, respectively, suggesting that the mechanical properties of the copolymer are little affected by the modification.

Fig. 7a and $\mathrm{b}$ presents the DSC curves obtained for PS and for MPS15, respectively, degraded with time. In both cases a decrease in $T_{\mathrm{g}}$ was observed. However, while for PS only a slight decrease occurred, for MPS the decrease was drastic. The different thermal behaviour of these polymers can be due to the differences in the segmental mobility in the amorphous region, since, as is well known, $T_{\mathrm{g}}$ is very sensitive to changes in chemical structure [4].

The large decrease of $T_{\mathrm{g}}$, observed for MPS15 with degradation results directly from the formation of shorter chains after bond cleavage. Formation of shorter chain molecules is an important step towards the degradation under environmental conditions.
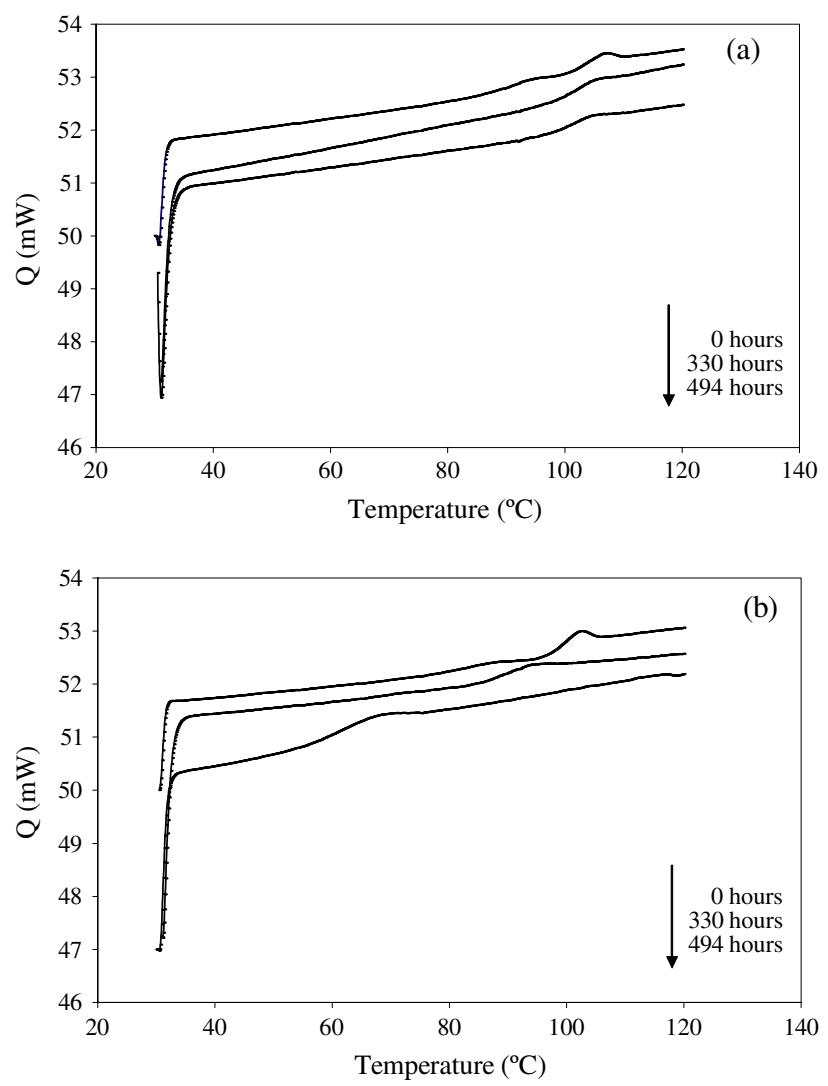

Fig. 7. DSC curves obtained for (a) PS and (b) MPS15, after different degradation times. 


\section{Conclusion}

In this work the influence of the modification introduced in polystyrene on its thermooxidative degradability has been investigated.

The lower stability of MPS in comparison with PS is reflected in its higher oxidation rate and yellowing. The formation of new carbonyl compounds, induced by the chemical modification, could be explained if carbon-carbon bond scissions occurred within the aliphatic segment. Such observations are supported by the decrease of the intrinsic viscosity and the drastic changes in the thermal behaviour of the modified polymers.

From the results obtained it is unequivocally concluded that the thermooxidative degradability of polystyrene could be enhanced after the insertion of aliphatic segments, containing carbonyl groups, within the polystyrene chain.

\section{References}

[1] Hamid SH. Handbook of polymer degradation-revised and expanded. New York: Marcel Dekker Inc.; 2000.

[2] McNeill IC, Zulfiqar M, Kousar T. Polym Degrad Stab 1990;28: 131.
[3] McNeill IC. Angew Makromol Chem 1997;247:179.

[4] Stack S, O'Donoghue O, Birkinshaw C. Polym Degrad Stab 2003; 79:29.

[5] Ferguson CJMG. Macromolecules 1990;23:2307.

[6] Park H, Pierce EM, Kwei TK. Macromolecules 1990;23:434.

[7] Chien YY, Pierce EM, Kwei TK. J Polym Sci Part A Polym Chem 1991;29:849.

[8] Mailhot B, Gardette JL. Macromolecules 1992;25:4119.

[9] Mailhot B, Gardette JL. Macromolecules 1992;25:4127.

[10] Bottino FA, Cinquegrani AR, Pasquale G, Leonardi L, Pollicino A. Polym Test 2004;23:405.

[11] Mailhot B, Morlat S, Gardette JL. Polymer 2000;41:1981.

[12] Mailhot B, Jarroux N, Gardette JL. Polym Degrad Stab 2000;68: 321.

[13] Kaczmarek A, Swiwtek M, Kaminska A. Polym Degrad Stab 2004;83:35.

[14] Frangiosa PC, Catalani LH. Polym Degrad Stab 2003;82:207.

[15] Sikkema K, Hanner MJ, Brennan DJ, Smith PB, Priddy DB. Polym Degrad Stab 1992;38:119.

[16] Kato M, Yoneshige Y. Makromol Chem 1973;164:159.

[17] Frangiosa PC. PhD thesis, Universidade de São Paulo, Brasil; 2002.

[18] Botelho G, Queirós A, Gijsman P, Liberal S. Polym Degrad Stab 2001;74:39.

[19] Botelho G, Queirós A, Gijsman P. Polym Degrad Stab 2001;73: 431.

[20] Giancaterina S, Rossi A, Rivaton A, Gardette JL. Polym Degrad Stab 2000;68:133.

[21] Allen NS, Edge M, Wilkinson A, Liauw CM, Mourelatou D, Barrio J, et al. Polym Degrad Stab 2001;71:113. 